\title{
CARACTERIZAÇÃO MINERALÓGICA E BENEFICIAMENTO DAS BENTONITAS DA REGIÃO DE CUBATI E PEDRA LAVRADA-PB
}

\author{
D. A. Tonnesen ${ }^{1}$, L. C. Bertolino ${ }^{1}$, A. B. Luz ${ }^{1}$, F. T. Silva ${ }^{2}$ e D. M. O. Timóteo ${ }^{1}$ \\ ${ }^{1}$ CETEM - Centro de Tecnologia Mineral, Ministério da Ciência, Tecnologia e Inovação \\ ${ }^{2}$ UFRJ - Universidade Federal do Rio de Janeiro, Centro de Tecnologia, Escola Politécnica, Departamento de \\ Engenharia Metalúrgica e de Materiais. \\ diegotonnedsen@gmail.com, Icbertolino@cetem.gov.br, adaobluz@cetem.gov.br, dtimoteo@cetem.gov.br, \\ flatesi@metalmat.ufr.br
}

\section{RESUMO}

O estado da Paraíba é responsável pela maior produção de bentonita bruta do país, oriunda de um dos maiores depósitos do Brasil, localizado no município de Boa Vista. Recentemente, novas ocorrências foram descobertas nas regiões de Cubati e Pedra Lavrada. Diante da expectativa de ampliação da produção mineral e da consolidação do estado como o maior produtor do país, este trabalho tem por objetivo a caracterização mineralógica e beneficiamento das argilas montmoriloníticas desses novos depósitos visando o seu uso como viscosificante mineral na formulação de fluidos de perfuração de poços de petróleo. As diferentes amostras foram caracterizadas por difratometria de raios $X$, microscopia eletrônica de varredura, ensaios de viscosidade e filtrado API.

PALAVRAS-CHAVE: Montmorilonita, ativação, caracterização mineralógica, bentonita.

\section{MINERALOGICAL CHARACTERIZATION AND TREATMENT OF BENTONITES FROM CUBATI AND PEDRA LAVRADA-PB REGION}

\section{ABSTRACT}

The state of Paraíba is responsible for the most part of bentonite production in the country, originated from the biggest deposits in Brazil located in Boa Vista. In anticipation of the expansion of mineral production and the Paraiba state consolidation as the largest producer in the country, the aim of this study was to develop the mineralogical characterization and treatment of the montmorillonite clay deposits aiming its use as a mineral component of oil well drilling fluids. For this, the samples were characterized by $x$-ray diffraction, scanning electron microscopy, viscosity and API filtered tests.

KEY-WORDS: Montmorillonite, treatment, mineralogical characterization, bentonite. 


\section{INTRODUÇÃO}

A bentonita é uma argila plástica e coloidal constituída, essencialmente, por montmorilonita e outros minerais do grupo das esmectitas, com outros componentes como: caulinita, ilita, feldspatos, anfibólios, cristobalita e quartzo. O total de componentes não argilosos na bentonita é, dificilmente, inferior a $10 \%$. Tais componentes apresentam cores variadas, tais como: branco, cinza, amarelo, marrom, verde e azul (Grim, 1968)

A bentonita, geralmente, possui a estrutura interestratificada entre membros da família das esmectititas e outros filossilicatos. A estrutura dos filossilicatos é composta pelas seguintes unidades estruturais: uma folha de tetraedros de sílica, ligados pelos oxigênios localizados nos vértices da base, e uma folha de octaedros de alumina ligados pelas faces laterais (Porto \& Aranha, 2010; Uskarei, 2006)

Neste tipo de estrutura, as folhas de tetraedros de lamelas diferentes encontram-se adjacentes, enquanto os átomos de oxigênio localizam-se em posições opostas, levando a uma fraca ligação entre as camadas. Além disso, existe forte potencial repulsivo na superfície das lamelas, resultante do desbalanceamento elétrico. Esses dois fatores contribuem para o aumento da distância entre as camadas, quando em presença de água, provocando o inchamento da argila.

As propriedades reológicas mais importantes da bentonita são a viscosidade e a tixotropia. A bentonita pode ser usada como agente controlador de viscosidade de um fluido de perfuração, de modo a permitir uma maior eficiência no transporte de fragmentos de rochas para a superfície. Quanto às propriedades tixotrópicas, estas são de grande importância, pois permitem que a suspensão assuma uma estrutura gelatinosa quando em repouso. Isso é importante, nos fluidos de perfuração, porque impede o retorno dos fragmentos de rochas ao fundo do poço, em casos como a paralisação do bombeamento para a troca de broca de perfuração ou na colocação de novas colunas de perfuração.

O uso de bentonita nos fluidos de perfuração também está relacionado à ação lubrificante, sobre a broca e as tubulações, e à formação de uma camada de baixa permeabilidade nas paredes do poço Desempenham uma série de funções essenciais dependentes diretamente das suas propriedades físicas e químicas, ou seja, densidade, viscosidade, consistência do gel, controle de filtrado e reboco e inibição das argilas hidratáveis (Barbosa et al., 2007). Na Tabela 1, constam as especificações para uso de bentonita em fluidos de perfuração de poços de petróleo baseado na dispersão de $24,3 \mathrm{~g}$ de argila em $500 \mathrm{~mL}$ de água destilada (Aranha, 2007).

Tabela 1. Requisitos da norma Petrobras N-2604.

\begin{tabular}{l|c|c}
\hline \multirow{2}{*}{ Características } & \multicolumn{2}{|c}{ Argila ativada } \\
\cline { 2 - 3 } & Mínimo & Máximo \\
\hline Viscosidade aparente (cP) & 15,0 & - \\
Viscosidade plástica (cP) & 4,0 & - \\
Retido na peneira ABNT 75 $\mu \mathrm{m}$ (\% peso) & - & 4,0 \\
Umidade (\%) & - & 14,0 \\
Ph & - & 10,0 \\
Filtrado API (mL) & - & 18,0 \\
\hline
\end{tabular}


É conhecido que, para uso como viscosificante mineral na perfuração de poços de petróleo, as bentonitas devem apresentar um alto grau de inchamento, característica presente preferencialmente nas bentonitas do tipo sódica (James et al., 2008). O íon $\mathrm{Na}^{+}$tem maior facilidade de hidratação do que o $\mathrm{Ca}^{2+}$. Além disso, quando as lamelas têm suas cargas compensadas pelo íon sódio, de menor valência, apresentam-se mais afastadas devido à menor energia de interação, de modo a permitir a penetração de uma maior quantidade de água no espaço entre as lamelas. Isso explica por que a capacidade de expansão da bentonita sódica é muito maior do que a do tipo cálcica. Para o uso de bentonitas do tipo cálcica, predominantes no Brasil, deve-se realizar uma etapa denominada de ativação com barrilha $\left(\mathrm{Na}_{2} \mathrm{CO}_{3}\right)$, em que os íons $\mathrm{Ca}^{2+}$ são trocados por íons $\mathrm{Na}^{+}$. Esse processo foi desenvolvido e patenteado na Alemanha, no ano de 1933, pela empresa Erblosh \& Co e é atualmente utilizado pelos países que não dispõem de bentonita sódica natural (Aranha et al., 2002; Luz e Oliveira, 2008; Menezes et al., 2009 e Baltar et al., 2003).

O arcabouço geológico presente no município de Cubati, é constituído pela Formação Campos Novos datando do Cenozóico, Granitóides de composição variada e Suíte calcialcalina de médio a alto potássio Itaporanga (ambos datando do Neoproterozóico) e Complexo SerrinhaPedro Velho (de idade Paleoproterozóica) CPRM (2002). A Formação Campos Novos é composta por arenitos localmente silicificados e argilitos, estes últimos explorados comercialmente pelo conteúdo de argilominerais do grupo das bentonitas, que ocorrem na região de Cubati, Pedra Lavrada e Boa Vista (PB), e ainda é constituída por basaltos e argila montmorilonítica.

\section{MATERIAIS E MÉTODOS}

\subsection{Amostragem e Preparação}

Foram coletadas três amostras de bentonita com aproximadamente $40 \mathrm{~kg}$ (Cinza CN, Clara $\mathrm{CN}$ e Cinza PL), sendo as duas primeiras do depósito Campos Novos, em Cubati e a última do depósito Campinhos, em Pedra Lavrada - PB (Figura 1). Foi utilizada a técnica de amostragem aleatória, onde os incrementos foram escolhidos de maneira fortuita, de modo que todas partes do material possuam a mesma probabilidade de serem selecionados. No CETEM, essas amostras foram secas ao sol por um período de $8 \mathrm{~h}$ e cominuídas em um britador de rolos. 0 produto da cominuição foi homogeneizado em pilha e dessa foram retiradas alíquotas para as etapas de caracterização mineralógica e beneficiamento.

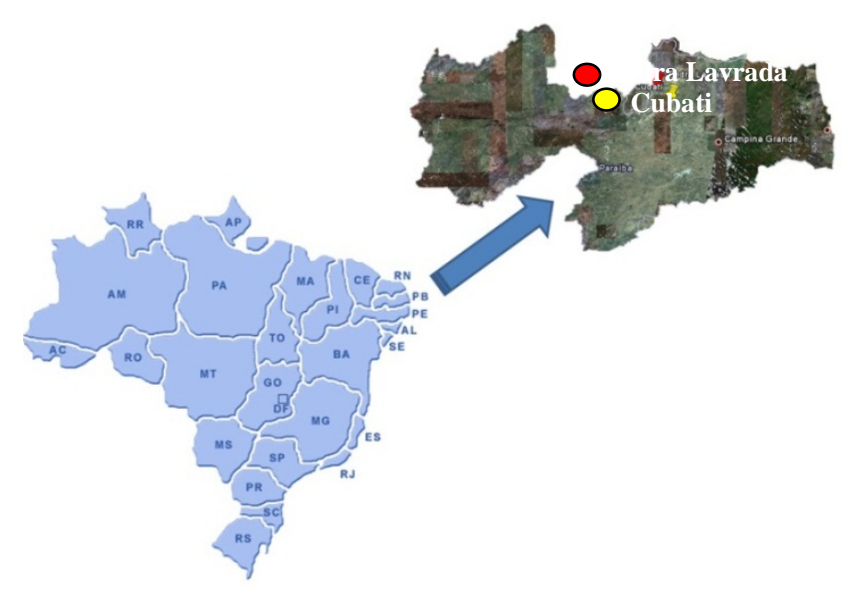

Figura 1. Localização dos depósitos de Cubati e Pedra Lavrada - PB. 


\subsection{Caracterização Mineralógica}

As análises utilizadas na caracterização das bentonitas dos novos depósitos da Paraíba foram: difratometria de raios - $X$ (DRX), microscopia eletrônica de varredura (MEV), fluorescência de raios- $X$ (FRX) e capacidade de troca catiônica (CTC).

Os difratogramas de raios $X$ foram obtidos em um equipamento Bruker-D4 Endeavor do CETEM, nas seguintes condições de operação: radiação Co $K \alpha(40 \mathrm{kV} / 40 \mathrm{~mA})$; velocidade do goniômetro de $0,02^{\circ} 2 \theta$ por passo, com tempo de contagem de 0,5 segundo por passo e coletados de 4 a 80 $2 \theta$, com detector sensível à posição LynxEye. As interpretações qualitativas de espectro foram efetuadas por comparação com padrões contidos no banco de dados PDF02 (ICDD, 2006), em software Bruker DiffracPlus. A difratometria de raios - $X$ foi o principal método utilizado na caracterização mineralógica das amostras de bentonita.

As análises no microscópio eletrônico de varredura (MEV) foram realizadas em um equipamento modelo Quanta 400 da Bruker do CETEM. As amostras foram metalizadas com prata e analisadas nos módulos elétrons secundários, elétrons retroespalhados e EDS.

As análises químicas por fluorescência de raios-X foram realizadas por uma varredura semiquantitativa em amostras previamente moídas abaixo de 0,074 $\mathrm{mm}$ e fundidas com tetraborato de lítio a uma temperatura de 1.000 으, na proporção de 1:6 amostra/fundente.

\subsection{Ensaios de Beneficiamento}

Os ensaios de beneficiamento das bentonitas de Cubati e Pedra Lavrada foram realizados no Laboratório de Minerais Industriais do CETEM e consistiram das seguintes etapas: ativação da bentonita, preparação da suspensão mineral, medições de $\mathrm{pH}$ das suspensões, testes de viscosidade para determinação da viscosidade plástica e aparente e ensaios de filtrado API.

As amostras foram ativadas com solução de carbonato de sódio $\left(\mathrm{Na}_{2} \mathrm{CO}_{3}\right)$ a $5 \%$, adicionadas de forma que o volume dispersado em cada alíquota correspondesse a 0,019,0,038, 0,057, 0,076 e 0,095 meq/100g de argila seca. Essas amostras foram colocadas em bandejas e vedadas com plástico para evitar a perda de umidade. Posteriormente, foram realizadas três coletas com intervalos de 24 horas (48, 72 e 96 h). Em seguida, as amostras foram desagregadas no moinho analítico, por 40 segundos, até obter a massa de $24,3 \mathrm{~g}$ na granulometria inferior a $0,074 \mathrm{~mm}$, de acordo com as normas da Petrobras.

Após o processo de ativação, os materiais coletados foram transferidos para um agitador Hamilton Beach, para a preparação de uma suspensão composta de $24,3 \mathrm{~g}$ de bentonita e $500 \mathrm{ml}$ de água destilada, sob agitação de $17000 \mathrm{rpm}$ durante $20 \mathrm{~min}$. Ao final desse procedimento, a suspensão foi transferida para um recipiente fechado, onde permaneceu em repouso por $24 \mathrm{~h}$.

Para os ensaios de viscosidade, foi utilizado um viscosímetro FANN modelo 35A. A suspensão preparada $24 \mathrm{~h}$ antes foi novamente agitada nas mesmas condições por um período de 5 min e transferida para o recipiente do viscosímetro, onde foram feitas as leituras em 600 rpm, após 2 min, e em 300 rpm, após $15 \mathrm{~s}$.

Após o ensaio de viscosidade, a suspensão foi retornada para o copo do agitador Hamilton Beach e agitada, novamente, durante $1 \mathrm{~min}$, na velocidade de $17000 \mathrm{rpm}$. Em seguida foi transferida para o filtro API FANN, modelo $12 \mathrm{~B}$ e filtrada, utilizando-se papel de filtro tipo 
Whatman no 50, a uma pressão de 100 psi, durante 30 min. O filtrado foi coletado em uma proveta com precisão de $0,2 \mathrm{ml}$.

\section{RESULTADOS E DISCUSSÕES}

\subsection{Caracterização Mineralógica}

A análise por difratometria de raios - X (Figura 2) indicou, nas três amostras de bentonita, são constituídas por montmorilonita (esmectita), caulinita e quartzo. A amostra bentonita cinza de Pedra Lavrada apresenta, ainda, uma indicação de ilita em sua composição.

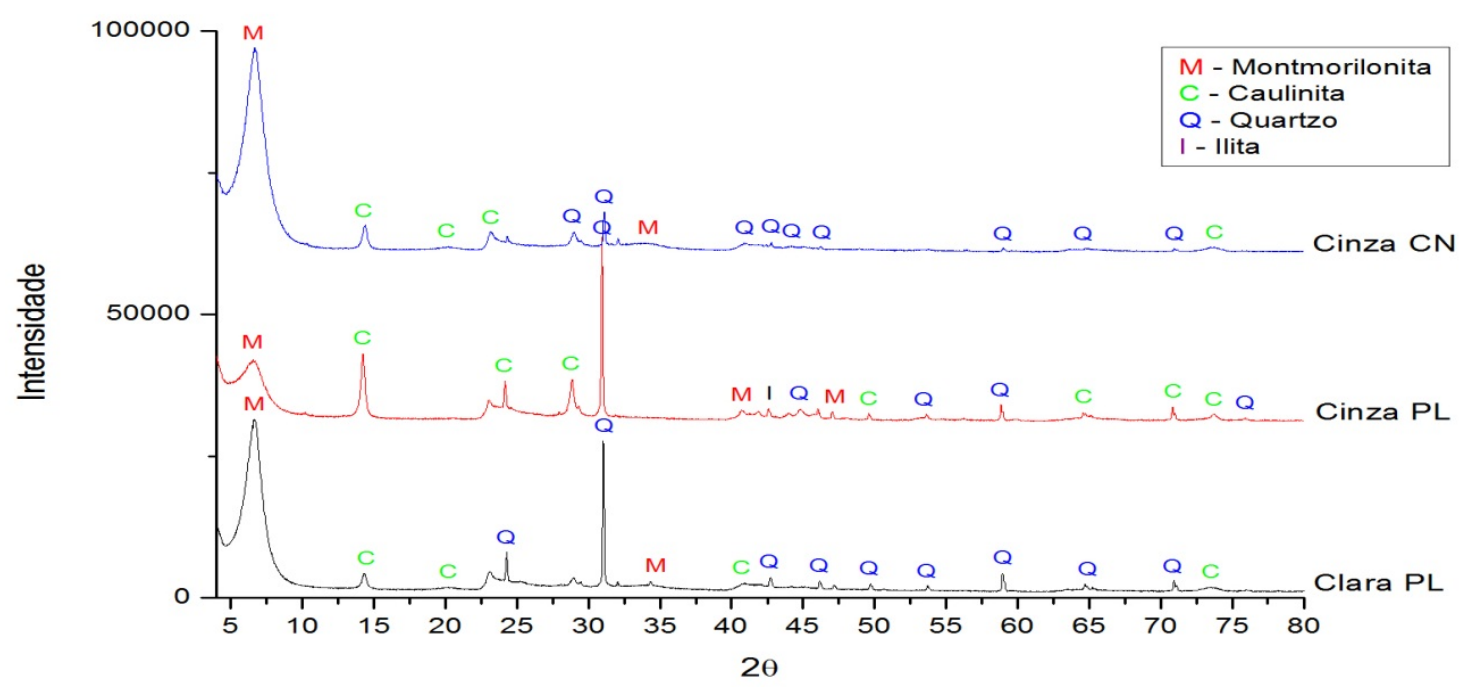

Figura 2. Difratogramas de raios - $X$ das amostras de bentonita estudadas. Co $K \alpha(40 \mathrm{kV} / 40 \mathrm{~mA})$.

A análise química das amostras de bentonita apresentada na Tabela 2, indica que o teor de Ca nas amostras é sempre superior ao teor de $\mathrm{Na}$, o que demonstra a importância do processo de ativação para o uso dessas bentonitas como viscosificante nos fluidos de perfuração de poços de petróleo. Além disso, o teor de $\mathrm{SiO}_{2}$ sendo bastante diferenciado nas três amostras analisadas, deverá refletir na viscosidade das suspensões preparadas. 
Tabela 2. Análise química das amostras de bentonita (\% em peso). PF = perda ao fogo

\begin{tabular}{c|c|c|c}
\hline & Clara - CN & Cinza-CN & Cinza - PL \\
\hline $\mathrm{Al}_{2} \mathrm{O}_{3}$ & 16,1 & 22,2 & 13,55 \\
\hline $\mathrm{BaO}$ & $\mathbf{0 , 0 2 3}$ & $\mathbf{0 , 0 3}$ & $\mathbf{0 , 0 1 8}$ \\
\hline $\mathrm{CaO}$ & $\mathbf{0 , 9 4}$ & $\mathbf{0 , 5 8}$ & $\mathbf{0 , 0 7}$ \\
\hline $\mathrm{Cr}_{2} \mathrm{O}_{3}$ & 0,018 & 0,026 & 0,01 \\
\hline $\mathrm{Fe}_{2} \mathrm{O}_{3}$ & 5,07 & 3,93 & 3,31 \\
\hline $\mathrm{K}_{2} \mathrm{O}$ & 0,314 & 0,75 & 0,304 \\
\hline $\mathrm{MgO}$ & 2,5 & 3,07 & 0,64 \\
\hline $\mathrm{MnO}$ & 0,016 & 0,015 & 0,02 \\
\hline $\mathrm{Na}_{2} \mathrm{O}$ & $\mathbf{0 , 2 7 8}$ & $\mathbf{0 , 5 2 4}$ & $\mathbf{0 , 1 1 2}$ \\
\hline $\mathrm{P}_{2} \mathrm{O}_{5}$ & 0,032 & 0,04 & 0,023 \\
\hline $\mathrm{SiO}$ & $\mathbf{6 5 , 6}$ & $\mathbf{5 6 , 5}$ & $\mathbf{7 5 , 7}$ \\
\hline $\mathrm{SrO}_{2}$ & 0,001 & 0,003 & $<0,001$ \\
\hline $\mathrm{TiO}_{2}$ & 0,68 & 0,82 & 0,82 \\
\hline $\mathrm{PF}$ & 7,63 & 9,34 & 5,05 \\
\hline $\mathrm{Total}$ & 99,202 & 97,828 & 99,627 \\
\hline
\end{tabular}

As imagens obtidas ao microscópio eletrônico de varredura (MEV), apresentadas na Figura 3, mostraram que as amostras são constituídas por aglomerados de argilominerais e quartzo, estando este distribuído na forma de pequenos grãos dispersos nas amostras. Na figura 4 é apresentado o EDS da amostra Cinza CN, em que foram obtidos os melhores resultados de viscosidade e filtrado API. 


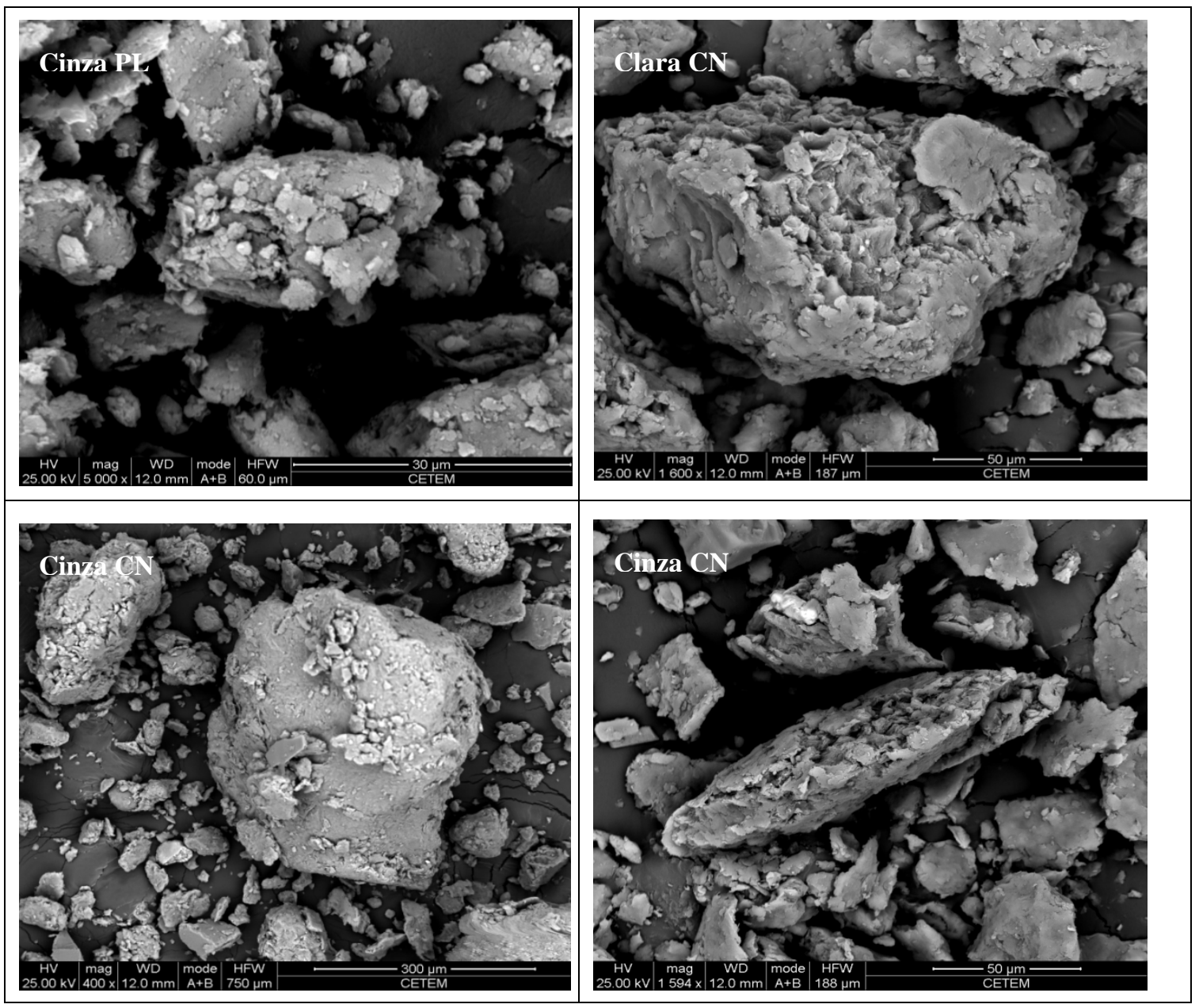

Figura 3. Imagens das três amostras de bentonita obtidas por MEV. Elétrons retroespalhados.

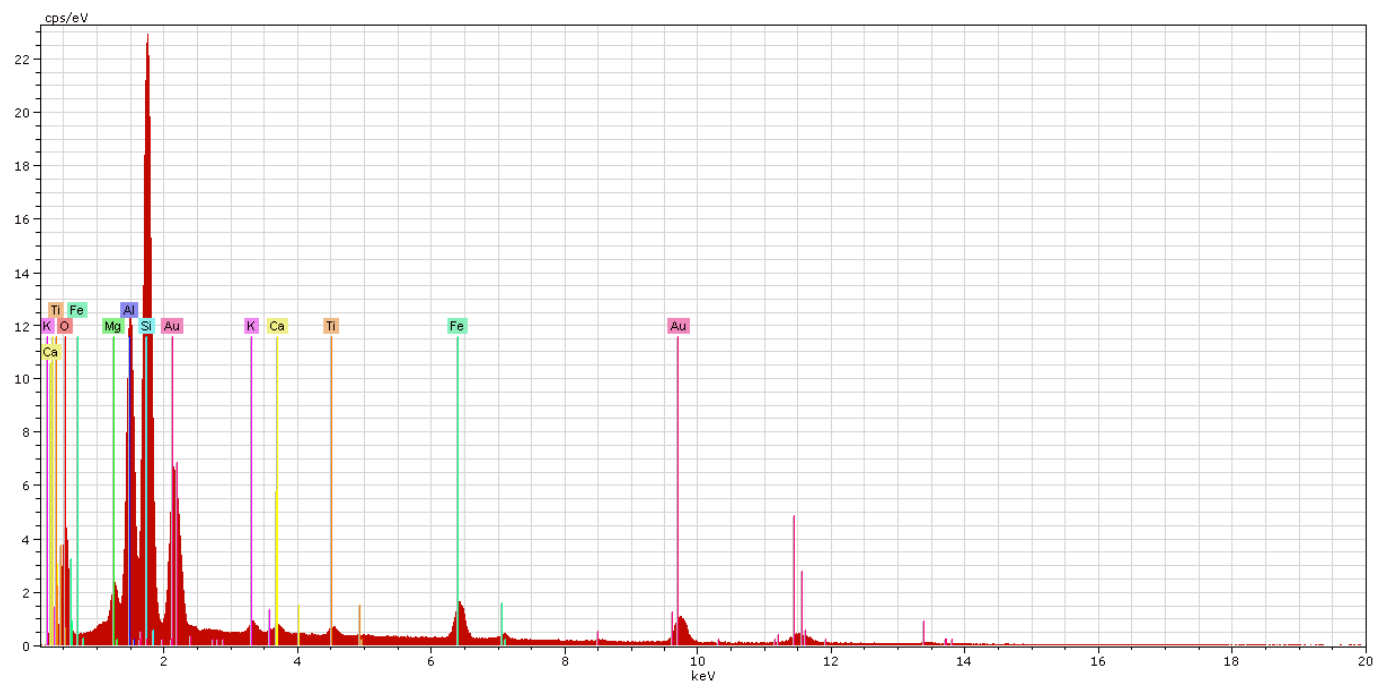

Figura 4. EDS da amostra de bentonita Cinza CN.

A análise da capacidade de troca de cátions das bentonitas de Campos Novos (CN) e Pedra Lavrada (PL) apresentou os resultados contidos na tabela 3 que também contém dados 
referentes as bentonitas de Boa Vista (BV) e Wyoming nos Estados Unidos para fins de comparação.

Tabela 3. Resultado da análise de capacidade de troca catiônica.

\begin{tabular}{c|c}
\hline Amostra & CTC (meq/100g) \\
\hline Cinza PL & 43,0 \\
\hline Clara CN & 49,1 \\
\hline Cinza CN & 53,5 \\
\hline Chocolate BV & $\mathbf{1 0 6 , 0}$ \\
\hline Chocobofe BV & $\mathbf{6 1 , 0}$ \\
\hline Bofe BV & $\mathbf{7 4 , 0}$ \\
\hline Verde Lodo BV & $\mathbf{5 4 , 0}$ \\
\hline Wyoming & $\mathbf{6 2 , 0}$ \\
\hline
\end{tabular}

Os valores de CTC esperados para bentonita variam de 60 a $170 \mathrm{meq} / 100 \mathrm{~g}$, nenhuma amostra analisada encontrou-se nessa faixa, provavelmente devido à presença de contaminantes, principalmente quartzo.

\subsection{Ensaios de Beneficiamento}

Os resultados dos testes de viscosidade em função da percentagem em peso de $\mathrm{Na}_{2} \mathrm{CO}_{3}$ adicionado na etapa de ativação são apresentados nas Figuras 5 e 6 para efeito de comparação entre os resultados obtidos com as argilas de Campos Novos e Pedra Lavrada e as argilas de Boa Vista. Os resultados de viscosidade plástica são apresentados na Figura 7. 




Figura 5. Variação da viscosidade aparente em função do tempo de cura e do percentual de $\mathrm{Na}_{2} \mathrm{CO}_{3}$.

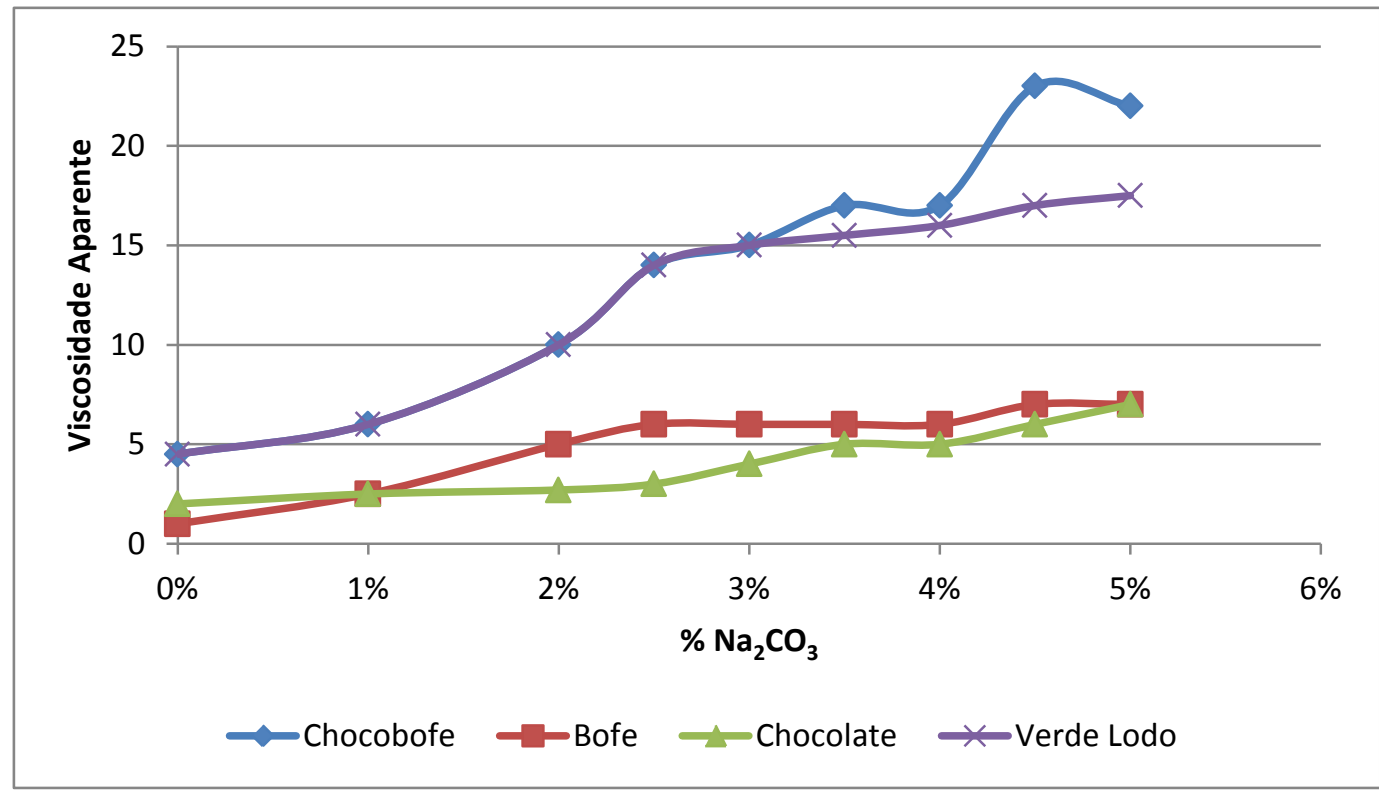

Figura 6. Variação da viscosidade aparente em função do percentual de $\mathrm{Na}_{2} \mathrm{CO}_{3}$ (Baltar et al., 2003) 


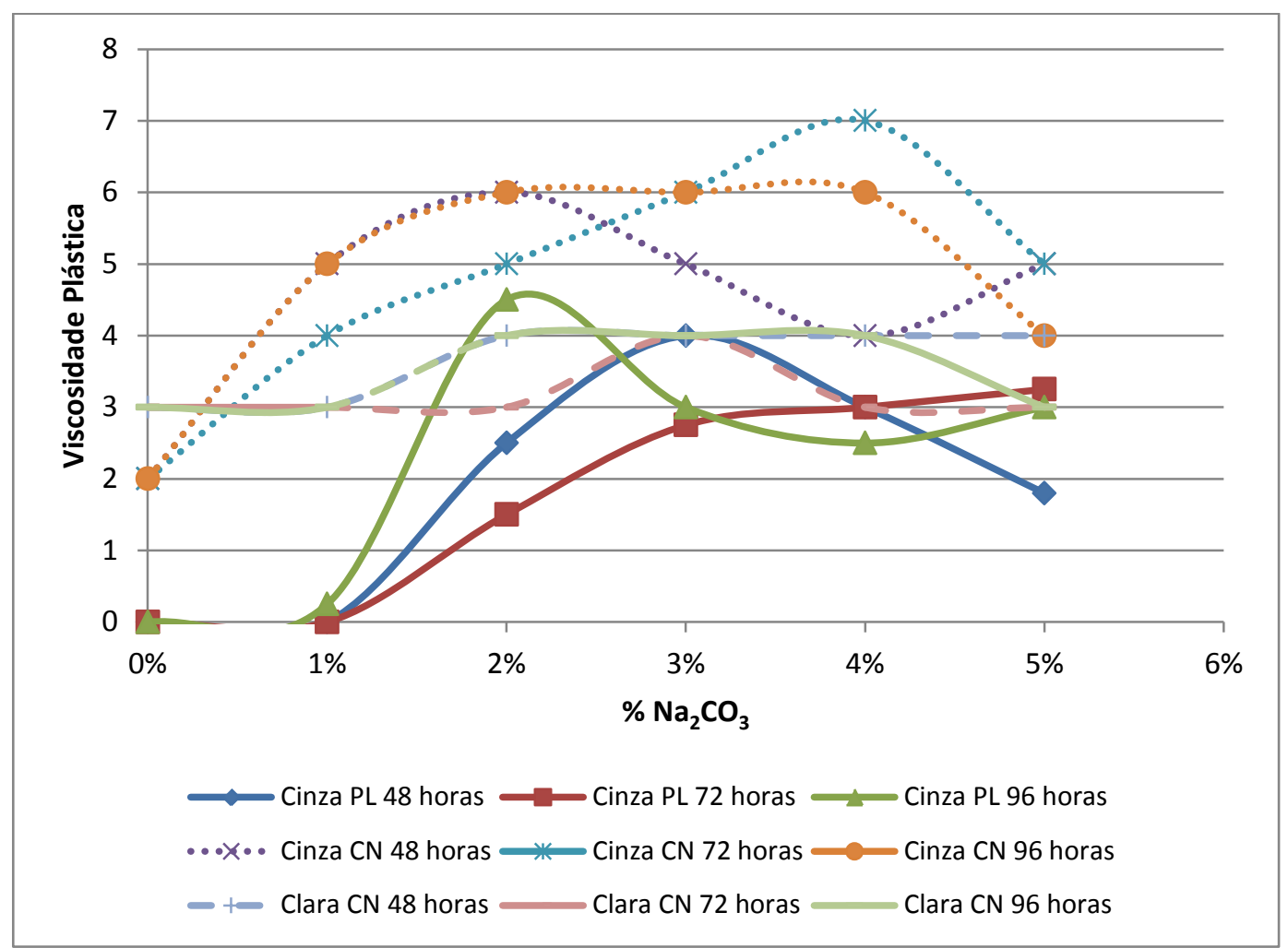

Figura 7. Variação da viscosidade plástica em função do tempo de cura e do percentual de $\mathrm{Na}_{2} \mathrm{CO}_{3}$.

Nota-se que, para a bentonita do tipo cinza $\mathrm{CN}$, a viscosidade aparente mínima requerida pela norma Petrobras 2605 (15 cP) é atingida quando a argila é ativada utilizando-se em torno de $3 \%$ de barrilha. Enquanto isso, para as bentonita do tipo clara CN e cinza PL mesmo utilizando-se $5 \%$ de barrilha na etapa de ativação, o requisito mínimo $(15 \mathrm{cP})$ não foi atingido. Além disso, não se observou uma influência significativa do tempo de ativação na viscosidade das suspensões. A análise dos dados obtidos para a viscosidade plástica não permitiu definir o comportamento desta variável em função do teor de $\mathrm{Na}_{2} \mathrm{CO}_{3}$, entretanto pode-se destacar que a bentonita cinza $\mathrm{CN}$ manteve valores de viscosidade plástica aceitos pela norma em todos os experimentos.

Os resultados obtidos nos ensaios de filtrado API podem ser vistos na Figura 8 e na Tabela 3, que apresenta, ainda, os valores de pH obtidos para as diversas suspensões em função do percentual de $\mathrm{Na}_{2} \mathrm{CO}_{3}$ usado na ativação. A análise dos resultados obtidos com a bentonita do tipo cinza $\mathrm{CN}$ indica que o processo de ativação é mais promissor, principalmente do ponto de vista do filtrado API obtido, sendo que os valores obtidos aproximam-se bastante do requisito da norma Petrobras 2604 (18 mL). 




Figura 8. Influência do teor de $\mathrm{Na}_{2} \mathrm{CO}_{3}$ nos valores de filtrado API.

Tabela 3. Valores de pH e filtrado obtidos para as diferentes amostras.

\begin{tabular}{|c|c|c|c|c|c|c|c|c|}
\hline Amostras & pH & $\begin{array}{c}\text { Filtrado } \\
\text { API }(\mathrm{mL})\end{array}$ & Amostras & $\mathrm{pH}$ & $\begin{array}{c}\text { Filtrado API } \\
(\mathrm{mL})\end{array}$ & Amostras & $\mathrm{pH}$ & $\begin{array}{l}\text { Filtrado API } \\
(\mathrm{mL})\end{array}$ \\
\hline Cinza CN & 7,65 & 23,5 & Clara CN & 9,77 & 40,4 & Cinza PL & 10,02 & 40,0 \\
\hline Cinza CN 1\% & 11,46 & 21,5 & Clara CN 1\% & 11,76 & 33,0 & Cinza PL 1\% & 10,51 & 38,6 \\
\hline Cinza CN 2\% & 11,78 & 19,0 & Clara CN 2\% & 11,99 & 28,2 & Cinza PL 2\% & 10,02 & 35,5 \\
\hline Cinza CN 3\% & 12,33 & 18,8 & Clara CN 3\% & 12,33 & 26,8 & Cinza PL 3\% & 10,06 & 38,0 \\
\hline Cinza CN 4\% & 12,35 & 18,6 & Clara CN 4\% & 12,39 & 26,4 & Cinza PL 4\% & 10,07 & 37,4 \\
\hline Cinza CN 5\% & 12,67 & 18 & Clara CN 5\% & 12,48 & 26,0 & Cinza PL 5\% & 10,02 & 41,0 \\
\hline
\end{tabular}

A respeito do $\mathrm{pH}$ das suspensões após o processo de ativação, somente a amostra cinza PL atendeu ao requisito da norma ( $\mathrm{pH}$ no máximo 10,0$)$, entretanto não atingiu a viscosidade mínima e volume máximo de filtrado especificado pela mesma. O mais notório foi o fato de a bentonita Clara $\mathrm{CN}$ natural já possuir um $\mathrm{pH}$ bastante elevado $(\mathrm{pH}=9,77)$. Para otimizar esse parâmetro serão necessários novos estudos, por exemplo, a fim de buscar uma fonte alternativa de sódio.

\section{CONCLUSÕES}

Os três tipos de amostras estudadas - cinza PL, cinza $\mathrm{CN}$ e clara $\mathrm{CN}$ - possuem picos característicos de montmorilonita (esmectita), caulinita e quartzo, com a amostra cinza PL apresentando ainda um pico correspondente a ilita. As indicações nos difratogramas apontam um maior teor de quartzo nas amostras cinza PL e clara CN. 
Os testes de viscosidade realizados foram satisfatórios apenas quando se utilizou a bentonita cinza CN. As bentonitas cinza PL e clara CN não atingiram o valor especificado na norma Petrobras, mesmo utilizando-se o teor máximo de $\mathrm{Na}_{2} \mathrm{CO}_{3}$ na etapa de ativação. Esse fato pode ser atribuído ao maior teor de quartzo presente nestas amostras.

Nenhuma amostra atingiu as especificações de filtrado API e pH da norma Petrobras 2604, entretanto os resultados obtidos com a bentonita cinza $\mathrm{CN}$ mostraram-se bastante promissores.

Cabe ressaltar que os resultados obtidos nesse estudo não podem ser generalizados para todo o depósito das fazendas Campos Novos e Campinhos. Para isso seria necessário um mapeamento geológico da região para que pudesse analisar as variações que ocorrem nas camadas ao longo do perfil geológico.

\section{AGRADECIMENTOS}

Os autores agradecem as empresas pelo fornecimento das amostras. Ao Centro de Tecnologia Mineral (CETEM) pela oportunidade de utilização dos seus laboratórios. Ao CNPq e a FAPERJ pelo apoio financeiro.

\section{BIBLIOGRAFIA}

1. ARANHA, I. B. Preparação, caracterização e propriedades de argilas organofílicas. 2007. 155 p. Tese (Doutorado) - Instituto de Química, Universidade Federal do Rio de Janeiro, Rio de Janeiro.

2. ARANHA, I. B.; OliVEIRA, C. H.; NEUMANN, R.; ALCOVER NETO, A.; LUZ, A. B.(2002) Caracterização Mineralógica de Bentonitas Brasileiras. In.: XIX Encontro Nacional de Tratamento de Minérios e Metalurgia Extrativa, Anais. Volume 1, Recife, 2002.

3. BALTAR, C. A. M.; LUZ, A. B.; OLIVEIRA, C. H.; ARANHA, I.B. Caracterização, ativação e modificação superficial de bentonitas brasileiras. In.: Insumos minerais para perfuração de poços de petróleo. Baltar, C.A.M.; Luz, A.B. (Editores), UFPE/CETEM-MCT, 21-46, 2003.

4. BARBOSA, M. I. R.; AMORIM, L. V.; BARBOZA, R. A.; FERREIRA, H. C. Desenvolvimento de compósitos bentonita/polímeros para aplicação em fluidos de perfuração. Matéria (Rio J.), Rio de Janeiro, v. 12, n.2, 2007. Disponível em http://www.scielo.br/scielo.php?script=sci_arttext\&pid=S1517-

70762007000200015\&lng=pt\&nrm=iso. Acessos em 08 fev. 2011. doi: 10.1590/S151770762007200015.

5. CPRM - Serviço Geológico do Brasil. Sistema de Informações Geográficas (SIG). 2002. (CDROM).

6. GRIM, R. E., Clay Mineralogy. McGraw-Hill.596 p, 1968.

7. JAMES, O. O., M. ADEDIRAN MESUBI, F. A. ADEKOLA, E. O. ODEBUNMI, J. I. D. ADEKEYE. Beneficiation and characterization of a bentonite from north-eastern Nigeria. Journal of the North Carolina Academy of Science. 124 (4). 2008. pp. 154-158.

8. LUZ, A. B.; OLIVEIRA, C. H. Argilas - Bentonita. In.: Rochas e Minerais Industriais - Usos e Especificações. Adão B. Luz; Fernando F. Lins. (Editores), CETEM-MCT, p.239-253, 2008.

9. MENEZES, R. R.; SOUTO, P. M.; SANTANA, L. N. L.; NEVES, G. A.; KIMINAMI, G. A.; FERREIRA, H. C. Argilas bentoníticas de Cubati, Paraíba, Brasil: Caracterização física-mineralógica. Cerâmica, 55, 163-169, 2009.

10. PORTO, J. P. P.; ARANHA, I. B. Caracterização Cristaloquímica Preliminar de Bentonitas Brasileiras. Anais da JIC, 2010. 
11. USKARCI, T. Behaviour of Bentonite Suspensions in Non-Aqueous Media. Thesis. Middle East Technical University, 2006. 110 p. 